\title{
ERRATUM
}

\section{Erratum to: Real-Life Safety and Effectiveness of Amlodipine/Valsartan Combination in the Treatment of Hypertension}

Irina E. Chazova $\cdot$ Neelesh Dongre $\cdot$ Alexey V. Vigdorchik

(C) Springer Healthcare 2011

Erratum to: Chazova IE, et al. Real-life safety and effectiveness of amlodipine/valsartan combination in the treatment of hypertension. Adv Ther. 2011;28(2):134-149.

In the investigator list of the above-mentioned paper (page 13), the list of participating physicians from Bangladesh was published with errors. The correct and complete list is shown below.

Bangladesh: Prof. A.K.M. Mohibullah, Prof. Khawaja Nazim Uddin, Dr. Serajul Haque, Dr. A.E.M Mazharul Islam, Dr. A.K.M. Shaheen Ahmed, Dr. Ferdous Hasan Apu, Dr. A.H. Hamid Ahmed, Dr. A.H.M. Shams ud Doha, Dr. Golam Mostafa, Dr. M.A. Rouf, Dr. Md. Ibrahim Chowdhury, Dr. Md. Shahabul Huda Chowdhury, Dr. Abu Tarek Iqbal, Dr. Uttam Kumar Saha, Dr. Goutam Kumar Roy, Dr. Md. Aminur Rahman Laskar, Dr. Biswanath Podder, Dr. Md. Mizanur Rahman, Dr. Borhanuddin Ahmed, Dr. Md. Mahbubur Rahman 